OLIVEIRA, A. L. A. M. Hermes e bonecas russas: um estudo colaborativo para compreender a relação teoria-prática na formação docente. 2006, 247f. Tese de doutorado. Programa de Pós-graduação em Linguística Aplicada. Universidade Federal de Minas Gerais. Belo Horizonte, 2006.

\title{
HERMES E BONECAS RUSSAS: PARA COMPREENDER A FORMAÇÃO DOCENTE
}

\section{Hermes and Russian dolls: understanding teacher development}

\section{Resenhado por: Katia Bruginski MULIK, UFPR-PG ${ }^{1}$}

Em sua tese de doutoramento defendida no ano de 2006, Ana Larissa A. M. Oliveira, professora da Faculdade de Letras da Universidade Federal de Minas Gerais (UFMG), propõe, em uma pesquisa-ação de caráter etnográfico, a discussão sobre a açãocolaborativa entre professores de língua inglesa. Pelo viés da linguagem, seu objetivo foi analisar os processos de construção e reconstrução do saber docente em uma situação de formação continuada com três professoras de escolas públicas. As referidas professoras eram participantes do Projeto de Educação Continuada de Professores de Línguas Estrangeiras na UFMG. O estudo de Oliveira divide-se em seis capítulos que serão explanados a seguir.

No primeiro capítulo a autora apresenta seu tema de estudo inserindo-o no paradigma pós-moderno. Este último é entendido por ela como uma forma de rever "dicotomias modernas, tais como a relação sujeito/objeto, pesquisador/pesquisado, saber científico/saber comum e a relação: teoria/prática" (OLIVEIRA, 2006, p. 15). Partindo do ideário freireano de crítica pela linguagem, a autora optou por verificar se a açãocolaborativa pode ser uma aliada na (re)construção do conhecimento, bem como na mudança da práxis de professores. O distanciamento da relação entre teoria e prática tem colaborado para um cenário de inconsistências no ensino de línguas, no sentido de que ambas são entendidas como elementos opositivos e não como partes integrantes de um todo. Por isso, Oliveira defende em seu trabalho que a escola precisa ser co-autora e coparticipante da produção do conhecimento vendo esse espaço, e os que nele circulam, não como objetos "descartáveis" para coletas de dados da pesquisas, mas como protagonistas.

\footnotetext{
1 Mestranda em Estudos Linguísticos pela UFPR.
} 
No capítulo dois, Oliveira apresenta os pilares teóricos de seu estudo: o paradigma crítico-reflexivo na formação de professores e a pesquisa-ação colaborativa. Inicialmente, a pesquisadora discorre sobre a importância do pensamento de Freire e a sua influência nos estudos da Linguística Aplicada. A autora coloca que os estudos da pedagogia crítica auxiliaram no desvelar do multifacetado fenômeno linguístico atentando para as implicações nos âmbitos sociais, culturais, políticos, econômicos, ideológicos e não apenas do pedagógico. A neutralidade da língua é posta em xeque e traz consigo a idealização do "falar como um nativo" reconhecendo assim outras formas de expressão como legítimas. Oliveira (2006, p. 29) advoga de forma assertiva que "a formação que parte dos professores de línguas recebe não lhes permite emancipação crítica suficiente para poderem escolher o que, o como e o porquê ensinar de modo crítico e teoricamente fundamentado". Diante dessa lacuna na formação, o professor passa a ser mero reprodutor de "modismos metodológicos" executados sem reflexão e sem mensuração dos impactos educacionais.

Ainda nesse capítulo, a autora comenta sobre a pedagogia pós-método proposta por Kumaravadivelu (2001). Diante dos princípios do pós-método de Kumaravadivelu e do que Oliveira defende em seu trabalho, a escola pode ser um espaço onde não apenas se reproduz a sociedade, mas um lugar onde é possível projetar a sociedade e a escola que se quer através de ações de autonomia dos agentes envolvidos no processo educativo. Ao longo da pesquisa, Oliveira utiliza o termo formação crítico-reflexiva de professores que incorpora os princípios da pedagogia crítica e do pós-método entendendo-os como complementares.

O terceiro capítulo é destinado à apresentação da metodologia utilizada. Primeiramente a autora delineia a caracterização da pesquisa etnográfica e, em seguida, estabelece a discussão sobre as noções da Análise do Discurso Anglo Saxônica e sua relação com o estudo. Posterior a isso, tem-se a descrição dos procedimentos de coletas de dados, os perfis das participantes, o cenário da pesquisa: o projeto de formação e as quatro escolas públicas. A autora ressalta que "não foi um trabalho neutro e nem tampouco de mão única" (OLIVEIRA, 2006, p. 50-51). Exemplo disso é a própria participação das pesquisadas na análise preliminar dos dados, que modificaram hipóteses iniciais interpretadas pela autora sobre os significados produzidos.

O construto tensão colaborativa, entendido como um movimento discursivo, é um termo utilizado por Oliveira para desenvolver o debate colaborativo provocado ao longo das seções. A análise discursiva dos dados recorreu a tal construto, o qual compreende 
quatro movimentos interacionais distintos, porém conectados entre si: enunciado gerador de tensão - enunciado gerador de debate produzido pela pesquisadora ou pelas participantes; tensão colaborativa - caracterizada pela recuperação por enunciados da fala do outro, na conciliação, no confronto e justificativa do que e porque foi dito; reflexão - explicitação de rupturas e tomadas de consciência pelas professoras e por último, a ação-transformadora - ações de mudança que se concretizaram e que foram descritas pelas professoras.

Em relação à coleta dos dados, esta se deu em duas etapas visando responder a questionamentos distintos. As perguntas norteadoras da etapa 1 foram:

- A teoria aprendida no projeto integra as práticas das professoras? Em que medida?;

- Como a linguagem é utilizada para debater criticamente a teoria divulgada no projeto nas interlocuções com a pesquisadora?

Já em relação à fase 2, a pergunta norteadora foi:

- A ação-colaborativa pode ser observável mesmo após as professoras perderem o contato com a rede de colaboração?

Dessa forma, a coleta se deu em dois momentos com instrumentos distintos. $\mathrm{Na}$ primeira etapa, Oliveira utilizou-se de observações em sala de aula, observações das professoras no curso de formação, sessões colaborativas entre professoras e pesquisadora, história de vida das participantes e diários feitos pelas participantes. Para a segunda etapa, denominada coleta tardia de dados, realizada dois anos depois da primeira, foram utilizados os procedimentos de observação de aulas das participantes e entrevista semiestruturada.

O quarto capítulo, no qual a análise é apresentada, divide-se em duas partes. $\mathrm{Na}$ primeira, a autora vale-se das questões norteadoras iniciais para descrever e interpretar três aulas observadas por ela tendo como referente o ensino da gramática como tema da ação-colaborativa (TAC). A segunda parte do capítulo descreve o percurso de reflexão das professoras em relação a certas concepções de ensinar tais como a produção oral dos alunos e o uso da língua inglesa na sala de aula que eram problemas comumente salientados no contexto de ensino onde atuavam. As professoras mostraram opiniões divergentes das iniciais em relação à própria noção de contexto e de uso significativo da língua, ou seja, o ensino voltado para práticas relacionadas ao cotidiano do aluno. Oliveira comenta que o processo de integração teoria-prática ocorreu disformemente entre as três professoras em um processo lento influenciado por aspectos econômicos, 
sociais, culturais e institucionais (principalmente em relação ao contexto distinto de escola pública e particular).

O quinto capítulo descreve a análise da segunda etapa de estudo feita com as professoras a qual é nomeada pela pesquisadora de coleta tardia dos dados, uma vez que estes foram gerados cerca de dois anos depois da primeira etapa realizada. Essa parte da investigação teve o intuito de verificar se havia ocorrido ou não mudança na postura crítica das pesquisadas mesmo após a perda de contato efetivo entre pesquisadora e participantes. Oliveira registra os aspectos significativos na mudança da práxis ${ }^{2}$ como, por exemplo, a mudança de rota no planejamento, os temas das aulas sempre recorrendo ao cotidiano dos alunos, o reconhecimento da identidade e das necessidades desses últimos, bem como uma maior conexão entre teoria-prática, pois "com base na prática a professora consegue teorizar e produzir heurística, encontrando soluções particulares para problemas específicos" (OLIVEIRA, 2006, p. 171). Nessa coleta tardia, a pesquisadora identificou, dentro de uma perspectiva crítica de mudança, três aspectos: disposição para mudar; a reaculturação, e a capacidade crítica para apropriar-se da teoria e produzir heurística.

O capítulo seis é destinado à discussão das considerações finais do estudo. Oliveira inicia fazendo uma síntese dos resultados, retomando o contexto em que se insere a pesquisa e seu propósito e a descrição do perfil de seus participantes. Em seguida, a autora inicia uma seção intitulada Hermes e bonecas russas: para compreender a formação docente na qual ela finalmente explica o título de sua tese. Oliveira argumenta que a essência do trabalho colaborativo, que visa à quebra de níveis hierárquicos e a manutenção do respeito à diferença dos participantes, pode ser traduzido pelo mito de Hermes o qual era visto na Mitologia Grega como um mediador, já que sabia falar tanto a língua dos deuses como a dos homens e dessa forma reduzia a distância entre o mundo divino e o mundano.

O mito também pode ser utilizado para representar a postura que pesquisadores e professores precisam assumir na transmissão do conhecimento, quer seja na sala de aula, quer seja na formação de profissionais que atuam ou que irão atuar nela. A aproximação dos dois universos por meio da linguagem deve se dar sem que sejam alteradas suas fronteiras e seus circulantes sejam reconhecidos com equidade. Oliveira advoga que com o trabalho colaborativo o objetivo não é que, as teorias sejam confirmadas na práxis, mas

\footnotetext{
${ }^{2}$ Apenas uma das professoras teve sua aula observada nessa coleta tardia, pois uma das professoras havia pedido afastamento temporário e a outra licença médica por problemas de saúde.
} 
que sejam ressignificadas, ou seja, modificadas e readaptadas aos contextos e a realidade de professores e alunos.

Já as bonecas russas são utilizadas, metaforicamente, para explicar que a tensão colaborativa é uma ação interdependente e que as bonecas que se encaixam umas nas outras possuem partes diferentes e, ao mesmo tempo iguais, formando um todo, fazem alusão ao crescimento tanto pessoal quanto profissional. Tal incorporação e transformação só são possíveis através da aprendizagem com o outro que, no contexto da pesquisa, se deu pela ação-colaborativa.

O estudo de Oliveira elucida a forte conexão entre teoria e prática que por muitos é vista de forma dicotômica. A autora mostra o quão importante é pensar como a teoria acontece na prática e como pode (e deve) ser adaptada para os contextos e realidades em que os sujeitos se encontram. A pesquisadora mostra também que o professor pode ser construtor de teoria através da própria práxis. Ela apresenta a ação-colaborativa como uma possibilidade de fazer com que, aliada à participação de cursos de formação, o professor reflita sobre a forma como e porque ensina. Além disso, as sessões colaborativas são reveladoras das crenças das professoras que, de forma crítica, foram postas em xeque apontando possíveis caminhos para a mudança. A troca de experiências acaba sendo o ponto alto do trabalho colaborativo, já que o objetivo não era identificar os possíveis problemas na prática das professoras, mas sim propor de forma conjunta, e com a participação ativa delas, possíveis formas de se repensar o ensino nas suas nuances de contexto, de conteúdo, etc.

Em relação à coleta tardia dos dados, penso que foi um dos pontos em que a pesquisa apresentou uma lacuna, já que só foi possível revisitar a prática de apenas uma das professoras. No entanto, mesmo que de forma restrita, a pesquisadora conseguiu mostrar que houve mudança e que a ação colaborativa tem caráter positivo. $\mathrm{O}$ trabalho de Oliveira pode ser comparado ao de Zellermayer e Morgolin (2005) que discutem o processo de mudança de professores trabalhando com a noção de comunidade de aprendizado colaborativo (collaborative learning community) através das lentes da teoria da complexidade. Outra noção interessante para se discutir a formação de professores é o conceito de agência que parte da noção freireana de práxis entendida como "uma prática reflexiva que desafia constantemente, em vários campos ideológicos, seus próprios pressupostos e desdobramentos, enfocando a transformação e constante reavaliação de procedimentos interpretativos de construção de sentidos" (JORDÃO, 2010, p. 438). 
É inquestionável que os professores precisam refletir sobre suas práticas, porém para que essa reflexão seja válida é preciso que seja direcionada. No trabalho em questão foi possível verificar como a tensão colaborativa pode gerar reflexão de forma "natural" e acabar contribuindo para que novas formas de ensinar sejam incorporadas. Outro ponto importante é fazer com que os professores reflitam em conjunto para que um possa auxiliar na resolução de conflitos e problemas do outro. Talvez momentos de tensão colaborativa possam ser incorporados a outros contextos de formação como, por exemplo, as semanas de formação pedagógica nas escolas fazendo desse momento não apenas um espaço para que os problemas sejam identificados ou para que o corpo docente possa "desabafar" as angústias vividas na sala de aula, mas sim, chegar próximo a, pelo menos, uma nova forma de lidar com elas.

\section{REFERÊNCIAS}

JORDÃO, C. M. A posição de professor de inglês no Brasil: hibridismo, identidade e agência. Let. \& Let. Uberlândia - MG. v. 26 n. 2, p. 427- 442 . jul/dez. 2010.

KUMARAVADIVELU, B. Toward a Postmethod Pedagogy. TESOL Quarterly. v. 35, $\mathrm{n}^{\circ}$ 4, p. 537-560, 2001.

ZELLERMAYER, M.; MARGOLIN, I. Teachers Educator's Professional Learning described through the Lens of Complexity Theory. Teachers College Record. Columbia University. v. 107, n. 6, June, 2005, p. 1275-1304. 